Research Article

\title{
Experimental Study on the Relationship between the Natural Frequency and the Corrosion in Reinforced Concrete Beams
}

\author{
Liye Zhang $\mathbb{D}^{1}{ }^{1}$ Limin Sun $\mathbb{D}^{2,3}$ and Lijuan Dong $\mathbb{D}^{4}$ \\ ${ }^{1}$ Research Institute of Highway Ministry of Transport, Beijing 100088, China \\ ${ }^{2}$ Department of Bridge Engineering, Tongji University, Shanghai 200092, China \\ ${ }^{3}$ State Key Laboratory of Disaster Reduction in Civil Engineering, Tongji University, Shanghai 200092, China \\ ${ }^{4}$ Beijing Baojiaheng Infrastructure Investment Co., Ltd., Beijing 100020, China \\ Correspondence should be addressed to Limin Sun; lmsun@tongji.edu.cn
}

Received 24 March 2021; Accepted 14 June 2021; Published 22 July 2021

Academic Editor: Haohui Xin

Copyright $\odot 2021$ Liye Zhang et al. This is an open access article distributed under the Creative Commons Attribution License, which permits unrestricted use, distribution, and reproduction in any medium, provided the original work is properly cited.

\begin{abstract}
Due to many nondamage factors such as temperature, humidity, carbonation, and corrosion effects on natural frequency, the key problem of the application frequency-based method to detect damage is to reveal the rules of these factors affect natural frequency and further to eliminate their effects. The long-term characteristics of reinforced concrete structures require a lot of attention, especially in corrosive environment. In this paper, an experimental investigation was conducted to study the deflection and natural frequency of reinforced concrete beam in a marine environmental chamber for six corrosion stages (accelerated corrosion for $0,20,40,70,100$, and 140 days). The experimental results demonstrated that deflection increases with corrosion time, while natural frequency decreases with corrosion time. Based on the accelerate corrosion test data of reinforced concrete beams, the general expression of the relationship between corrosion depth and natural frequency has been established through the fitting curve method. The polynomial model has been selected for establishing the relationship between steel corrosion depth (including the main reinforcement and stirrup) and natural frequency. The reason for selecting the polynomial model is that the sum of squares due to error (SSE) is closer to 0 and the coefficient of multiple determination ( $R$-square) is closer to 1 . This investigations help to discriminate the cause of reinforced concrete beams natural frequency change, to eliminate nondamage factors affects, and to apply many structural damage identification methods effectively.
\end{abstract}

\section{Introduction}

The interaction between reinforced concrete (RC) structures and the environment, including such factors as the temperature, humidity, carbonation, and corrosion, may produce significant deterioration in a structure's stiffness [1-4]. Steel corrosion give rise to cross-sectional area loss or stiffness loss in RC structures $[5,6]$. As is well known, structural damage would change the structural natural frequency. A great many structural damage detection techniques have been proposed for assessing damage location and severity based on changes in frequencies, mode shapes, or their combinations [7-9]. The identification of a structure's natural frequency is a significant task in structural health monitoring (SHM), since it is a critical parameter in structural damage assessment $[10,11]$. Once a structure's modal characteristics have been obtained, the change of structural stiffness should be predictable $[12,13]$. Many damage assessment methods have achieved better results in theory and experiments [14-16]. In practice, natural frequencies are influenced not only by damage, but also by nondamage factors, including temperature, humidity, concrete carbonation, and steel corrosion [17-19]. The effects of these nondamage factors can be large enough to mask changes in natural frequency caused by damage. Therefore, many damage identification methods are not feasible because the effects of these nondamage factors are particularly obvious in existing bridge structures.

In order to apply modal parameters such as natural frequency to accurately identify damage, we need to 
discriminate between the reasons for changes in natural frequency and to eliminate the effect of nondamage factors such as temperature, humidity, concrete carbonation, and steel corrosion when we identify a structure's natural frequency. The good news is that many scholars focus on this research field. Nandan and Singh [20] examined variations in the modal frequencies of concrete box girder and T-beam bridge structures caused by ambient temperature, solar irradiance, and wind speed, utilizing the environmental data recorded at a site in North Carolina, USA. Zhang and Sun [21] investigated the effect of concrete carbonation on the natural frequency of RC beams in an acceleration carbonation experiment. Many researchers have started to pay attention to research the effect of corrosion on natural frequency [22]. Gillich et al. [23] studied natural frequency changes due to severe corrosion in metallic structures. He and his research team developed two mathematical relations for predicting the frequency changes due to the main effect of corrosion: loss of mass and loss of stiffness. Razak and Choi [24] studied the effect of general corrosion on RC beam modal parameters and obtained that the trend in the measured natural frequencies was sensitive to the deterioration state of the beams. Rahgozar and Sharifi [25] studied remaining fatigue life of corroded steel structural members. Damage assessment needs to consider the effect of long-term environmental factors, especially in corrosive environment. Zhou et al. [26] studied mechanisms of thermally induced deflection of a long-span cable-stayed bridge. Due to the rules of the effect of steel corrosion on structural natural frequency are unclear, it is difficult to identify the frequency changes caused by structural damage, which results in the fact that many structural damage identification methods cannot be applied in actual engineering. To study this problem more comprehensively and to develop models for estimating frequency changes under corrosion conditions, it is quite necessary to study the relationship between corrosion depth and natural frequency through an experimental investigative approach. That is the purpose of this study.

The main objective of this paper is to establish the relationship between corrosion depth and the natural frequency of RC test beams. The authors reported the rules of corrosion depth and natural frequency based on an accelerated corrosion test of RC test beams. Based on an analysis of the test data from five RC test beams, the general expression for corrosion depth and natural frequency has been achieved using a curve fitting method. The findings of this study help to discriminate the cause of reinforced concrete natural frequency change, to eliminate nondamage factors affects, and to apply many structural damage identification methods effectively. It provides useful insight and a suitable model for application of modal parameters in a structural health monitoring (SHM) system to detect damage and perform a structural assessment of concrete structures.

The sections of this paper are as follows: in Section 2, the experimental study is introduced. Firstly, experimental setup including marine environmental chamber, reinforced concrete test beam, and its boundary conditions is described. Then, experimental environment and test stages, static test, dynamic test, and steel corrosion rate test are demonstrated. In Section 3, the experimental results are analyzed and given further discussion. Firstly, the steel corrosion rate, static and dynamic test results are introduced. Then, the relationship between the natural frequency and corrosion depth is analyzed. In addition, the effect of composition of concrete mixes on corrosion is discussed. Finally, the main conclusions are drawn in Section 4.

\section{Experimental Study of RC Beams after Being Exposed to a Corrosive Environment}

\subsection{Experimental Setup}

2.1.1. Marine Environmental Chamber. The purpose of this experiment is to investigate the effect of steel corrosion on the natural frequency of RC structures. In order to simulate a marine environment, the marine environmental chamber, which measured $5 \mathrm{~m}$ long and $3 \mathrm{~m}$ wide, was used to accelerate the corrosion process. This marine environmental chamber can control temperature, humidity, and the concentration of salt fog. The temperature adjustment range is 0-70 degrees Celsius, the humidity adjustment range is 0-100 percent, and the concentration of the salt fog depends on the amount of salt in the brine and is usually controlled 5-20 percent. This marine environmental chamber can meet the needs of simulating marine environment.

2.1.2. Reinforced Concrete Test Beam and Its Boundary Conditions. Five RC test beams (C30N01 C30N05), with a length of $3.2 \mathrm{~m}$, a width of $0.15 \mathrm{~m}$, and a height of $0.12 \mathrm{~m}$, were prepared for the accelerated corrosion experiment. Figure 1 shows detailing information of the main reinforcement and stirrup. These RC test beams were poured using a concrete of strength grade 30 .

Boundary conditions significantly affect the test results of natural frequency of an RC test beam. Therefore, stable boundary conditions need to be provided in the whole experiment process. Two pairs of support abutments, which include hinged and fixed-pin supports, were prepared for installing the RC test beams. Support abutments were poured using concrete of strength grade 40 . In order to maintain stability under marine environment, nuts, bolts, hinged supports, and steel plates were made from stainless steel. We can ascertain that the test results of deflection and natural frequency would not be affected by boundary conditions.

\subsection{Experimental Environment and Test Stages}

2.2.1. Marine Environmental Chamber Control Parameters. $\mathrm{RC}$ test beams (C30N01 C30N05) were subjected to static and dynamic testing at every accelerated corrosion stage, that is, at accelerated corrosion days $0,20,40,70,100$, and 140 in the marine environmental chamber, respectively. For more realistic simulation of atmospheric environment, we carried out the accelerated carbonation test in the carbonation experimental chamber for 28 days first. Then, these RC 



FIGURE 1: Detailing information of the main reinforcement and stirrup (units: $\mathrm{mm}$ ).

test beams underwent accelerated corrosion testing in the marine environmental chamber. In order to decrease the effects of such environmental factors as temperature and humidity, these RC test beams were kept for three days at a steady temperature (40 degrees Celsius) and humidity (100 percent) before being exposed to accelerated corrosion. Furthermore, static and dynamic tests at each corrosion stage needed to be completed within three hours after opening the marine environmental chamber's door.

Several researchers have concluded that the chloride ion erosion rate increases with temperature when the environmental temperature is below 40 degrees Celsius [27-29]. Therefore, in this experimental study, the steady parameters of the marine environmental chamber were as follows: temperature, 40 degrees Celsius (104 Fahrenheit); humidity, 100 percent; saline water concentration, 15 percent.

2.2.2. Test Stages of the Reinforced Concrete Beams. Six test stages (stage $0 \sim 5$ ) were studied as part of the whole experimental process. The first stage (stage 0 ) was the initial stage, before accelerated corrosion took place in the marine environmental chamber. The other five stages (stages 1 5) involved exposure to a $\mathrm{Cl}$-rich atmosphere in the marine environmental chamber at 20,40,70,100, and 140 days, which are defined as accelerated corrosion stage 1, stage 2 , stage 3 , stage 4 , and stage 5 , respectively.

The testing stages of the RC test beams are shown in Table 1. The C30N01 RC test beam underwent static testing and dynamic testing at stage 0 and stage 1 ; then was moved outside the marine environmental chamber to undergo corrosion rate testing. The $\mathrm{C} 30 \mathrm{~N} 03 \mathrm{RC}$ test beam underwent both static and dynamic testing at stage 0 through stage 2 , before being moved outside the marine environmental chamber to undergo corrosion rate testing. The C30N02 RC test beam went through static testing and dynamic testing at stage 0 through stage 3 , before being moved outside the marine environmental chamber for corrosion rate testing. The C30N05 RC test beam underwent static testing and dynamic testing at stage 0 through stage 4 and then was moved outside the marine environmental chamber for corrosion rate testing. The C30N04 RC test beam underwent static testing and dynamic testing at stage 0 through stage 5 ; then it was moved outside the marine environmental chamber for corrosion rate testing. Corrosion rate testing of the RC test beams were carried out within seven days after their removal from the marine environmental chamber.

2.3. Static Test and Dynamic Test. A deterioration of the structural stiffness would lead to not only a change in natural frequency but also a change in deflection. Due to the limitation of marine environmental chamber space, concrete blocks were used as the loading setup in the static test. The concrete block load weights are shown in Table 2. The total weight of the concrete blocks was $55.35 \mathrm{~kg}$, and the distribution plate was $8.36 \mathrm{~kg}$, placed on the midspan of the RC test beams. Figure 2(a) shows the details of the static test. The laser displacement meter was used to measure the midspan deflection at each test stage (when the RC test beams had been exposed to the accelerated corrosion environment for $0,20,40,70,100$, and 140 days, respectively) due to its high precision. The precision and measurement range of the laser displacement meter are $0.001 \mathrm{~mm}$ and $8 \mathrm{~mm}$, respectively. 
TABLE 1: Testing stages of the RC test beams.

\begin{tabular}{|c|c|c|c|c|c|c|}
\hline \multirow{2}{*}{ RC test beam No. } & \multicolumn{6}{|c|}{ Exposure time (day) } \\
\hline & 0 (stage 0$)$ & 20 (stage 1$)$ & 40 (stage 2) & 70 (stage 3 ) & 100 (stage 4$)$ & 140 (stage 5 ) \\
\hline C30N01 & $\mathrm{S} / \mathrm{D}$ & $S / D$ & - & - & - & - \\
\hline C30N03 & $\mathrm{S} / \mathrm{D}$ & S/D & S/D & - & - & - \\
\hline C30N02 & $\mathrm{S} / \mathrm{D}$ & $\mathrm{S} / \mathrm{D}$ & $S / D$ & $S / D$ & - & - \\
\hline C30N05 & $\mathrm{S} / \mathrm{D}$ & $\mathrm{S} / \mathrm{D}$ & $\mathrm{S} / \mathrm{D}$ & $\mathrm{S} / \mathrm{D}$ & $\mathrm{S} / \mathrm{D}$ & - \\
\hline C30N04 & $\mathrm{S} / \mathrm{D}$ & S/D & S/D & $S / D$ & $\mathrm{~S} / \mathrm{D}$ & S/D \\
\hline
\end{tabular}

Notes: $\mathrm{S}$ denotes static test and $\mathrm{D}$ denotes dynamic test.

TABLE 2: Weight of concrete blocks as load.

\begin{tabular}{lccc}
\hline Serial number & Weighing $(\mathrm{kg})$ & Serial number & Weighing $(\mathrm{kg})$ \\
\hline N01 & 16.85 & N04 & 7.45 \\
N02 & 7.75 & N05 & 7.95 \\
N03 & 7.60 & N06 & 7.75 \\
\hline
\end{tabular}

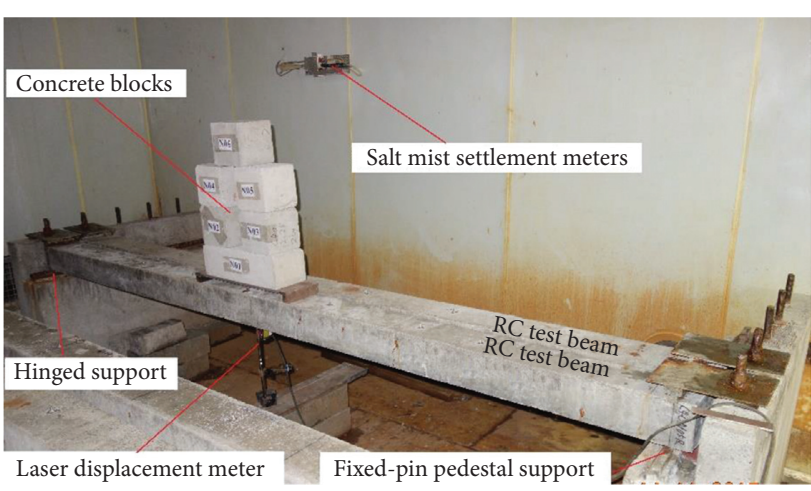

(a)

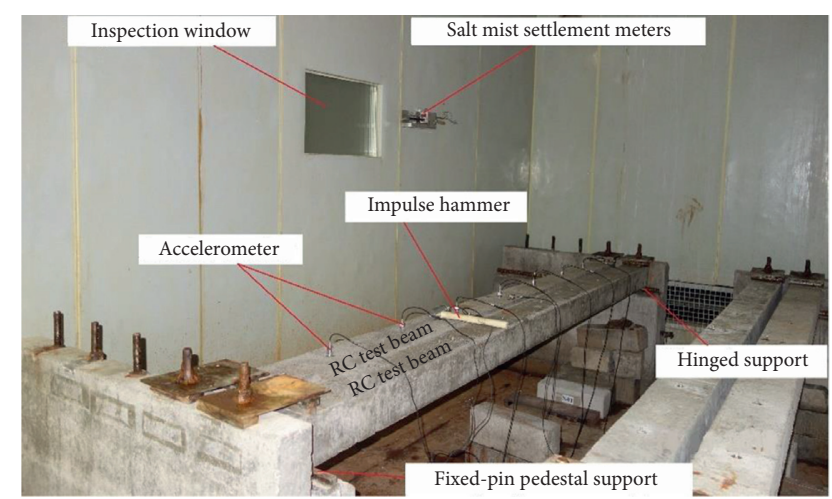

(b)

FIgURE 2: Experimental layout in the marine environmental chamber: (a) static test and (b) dynamic test.

The displacement value was obtained when the reading of the laser displacement meter was stable.

RC test beams were subjected to dynamic testing at the end of each accelerated corrosion stage that accelerated corrosion after $0,20,40,70,100$, and 140 days, respectively. Figure 2(b) shows the dynamic test of RC test beam in the marine environmental chamber. Seven piezoelectric accelerometers were installed on top of the RC test beam. The accelerometer evenly distributed on the RC test beam. The impulse method was used to test natural frequency. The details of the dynamic test method are described in the previous related research [21].

2.4. Steel Corrosion Rate Test. The weight method was used to measure the steel corrosion rate, according to

$$
R_{s}=\frac{W_{0}-W_{n}}{W_{0}} \times 100 \%,
$$

where $R_{s}$ denotes the steel corrosion rate, $W_{0}$ denotes the initial weight of steel, and $W_{n}$ denotes the weight of steel at corrosion stage $n$.

An electronic balance (model BL-4000F) was used to measure the weight of the steel with high precision. The reading accuracy of the electronic balance was $0.01 \mathrm{~g}$, and the weight range was $4 \mathrm{~kg}$ (the theoretical weight of each main reinforcement bar is about $2 \mathrm{~kg}$ ). For every steel measurement, the average of three weights was taken as the measured value in order to increase precision. Moreover, for every RC test beam, the initial weight of the steel was obtained before the concrete was poured. The weight of the steel at corrosion stage $n$ was obtained after dissecting the RC test beam and removing the rusted steel.

\section{Experimental Results and Discussion}

3.1. Steel Corrosion Rate Test Results. In accelerated corrosion stages $0 \sim 5$, that is, accelerate corrosion for $0,20,40,70$, 100 , and 140 days, the midspan deflection and natural frequency were tested in the marine environmental chamber. After each test stage, one RC test beam was moved outside the marine environmental chamber. It is already mentioned above that Table 1 shows the serial numbers of the RC test beams that underwent static and dynamic testing. The RC test beam that had been moved outside the marine environmental chamber was dissected, and the main reinforcement and stirrup were got out. A typical main reinforcement and stirrup (C30N05 RC test beam) following 
accelerated corrosion are shown in Figure 3. It is clear that the main reinforcement and stirrup were severely corroded. The rusted steel was removed via a sander. To prevent rust again affecting the test data, the weight of the steel at the corrosion stage was measured within three hours after the rust removal by a precision electronic balance (model BL$4000 \mathrm{~F}$ ) with a reading accuracy of $0.01 \mathrm{~g}$. The weight range of the electronic balance (about $4 \mathrm{~kg}$ ) is greater than each of main reinforcement weight (about $2 \mathrm{~kg}$ ). For each steel measurement, the average of three weights was taken as the measured value in order to increase the precision. Compared with the initial weight of steel, the corrosion rate was calculated according equation (1). Figure 4 demonstrates the main reinforcement and stirrup corrosion rate results for each RC test beam (C30N01 C30N05). The corrosion rates of the six main reinforcements in each beam section are shown. MRCR denotes the mean value of the main reinforcement corrosion rate, and SCR denotes the mean value of the stirrup corrosion rate. We can see that the maximum mean value of MRCR is -1.492 percent, and the maximum mean value of SCR is -4.083 percent, which is the C30N04 $\mathrm{RC}$ test beam at 140 -day accelerated corrosion.

3.2. Static and Dynamic Test Results. Theoretical analysis shows that if the concentrated load $P$ is applied at the middle of the simply supported beam span, the midspan deflection is inversely proportional to its stiffness. At the same time, many scholars obtained that changes in the modal parameters especially natural frequencies were sensitive to the deterioration state of the concrete beams. Razak and Choi suggested that the natural frequency of the simply supported beam is proportional to the stiffness EI, and the stiffness reduction is square the frequency reduction [24]. Of course, the above results are obtained based on liner analysis. Steel corrosion and rust product expansion caused concrete cracking which is a typical nonlinear process. Due to the concrete rust expansion cracks are random occurrence, theoretical analysis and FE simulation are difficult to achieve ideal results, and the experimental study is an effective method. So far, there are no equations that establish the relationship between the natural frequency and corrosion time or depth. In this experiment, the deflection, natural frequency, and corrosion rate of each corrosion stage were obtained. Several curve fitting methods, such as exponential, polynomial, and power, were selected for optimizing the experimental data. To avoid overfitting, each RC test beam is measured multiple times to increase the amount of test data. Various curve fitting methods were used to study the experiment data including the relationships between deflection and corrosion time and natural frequency and corrosion time. In addition, two parameters, (1) the sum of squares due to error (SSE) and (2) the coefficient of multiple determination (R-square), were used to evaluate the effect of the fitting model. SSE measures the deviation of the responses from the fitted values of the responses. A value of SSE closer to 0 indicates a better fit. R-square measures how successful the fit is in explaining the variation of the data. A value of $\mathrm{R}$-square closer to 1 indicates a better fit. The optimizing

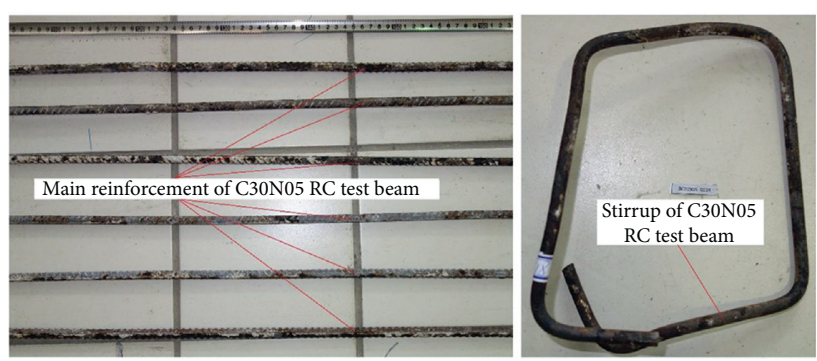

Figure 3: Main reinforcement and stirrup after accelerated corrosion (C30N05).

curve fit expression for deflection $\left(d_{e f}\right)$ and corrosion time $(t)$ are shown in Table 3.

According to the numerical value of SSE and R-square, the best general expression is one exponential functions. Equation (2) demonstrates a general expression of deflection $\left(d_{e f}\right)$ and corrosion time $(t)$ where SSE is $0.00002 \mathrm{~mm}$ and $\mathrm{R}$-square is 0.9981 , reflecting the relationships between deflection $\left(d_{e f}\right)$ and corrosion time $(t)$ :

$$
d_{e f}=0.441 e^{1.783 \times 10^{-3} t}+3.955 \times 10^{-17} e^{0.242 t} .
$$

In this experimental investigation, the natural frequency and deflection were tested at the same time. These two parameters can reflect structural stiffness change. Figure 5 shows that the deflection increases with the decrease of structural stiffness and that the natural frequency decreases with the decrease of structural stiffness. We therefore could establish the relationship between deflection and corrosion time, as well as the relationship between natural frequency and corrosion time. It is very important for the actual application of this model to consider environmental corrosion factors. Table 4 shows several fitting curves of frequency $(f)$ and corrosion time $(t)$.

Considering the analysis results of two kinds of fitting effectiveness evaluation indexes, we established the relationship between natural frequency $(f)$ and corrosion time $(t)$ expressed as equation (3) due to its SSE closer to 0 and an $\mathrm{R}$-square closer to 1 :

$$
f=23.33 e^{-5.38 \times 10^{-4} t}+1.135 \times 10^{-5} e^{6.746 \times 10^{-2} t} .
$$

Figure 5(a) shows the test data on deflection at each corrosion stage. The curve fitting between deflection $\left(d_{e f}\right)$ and corrosion time $(t)$ is obtained through the exponential model. Figure 5(b) demonstrates the test data of natural frequency at each corrosion stage. The curve fitting between frequency $(f)$ and corrosion time $(t)$ is obtained through an exponential model. We can see that the accelerated corrosion time is 140 days in the marine environmental chamber, where the temperature is 40 degree Celsius (104 Fahrenheit), the humidity is 100 percent, and the saline water concentration is 15 percent which are differences between the actual environment and marine environmental chamber. The transition and prediction method between the accelerated corrosion environment and the actual environment will be studied and reported upon in the future. 


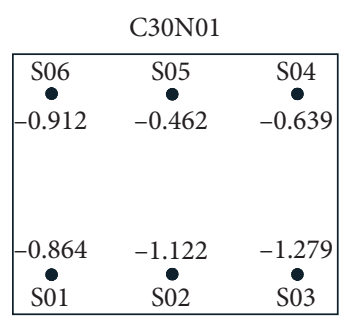

MRCR $=-0.880 \%$

$\mathrm{SCR}=-2.585 \%$

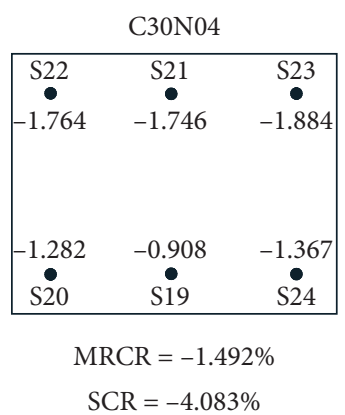

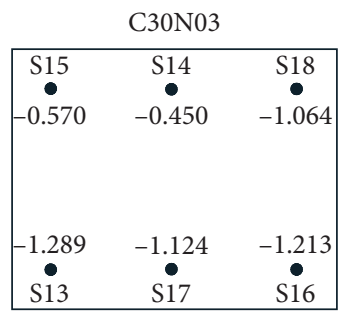

MRCR $=-0.952 \%$

SCR $=-2.810 \%$

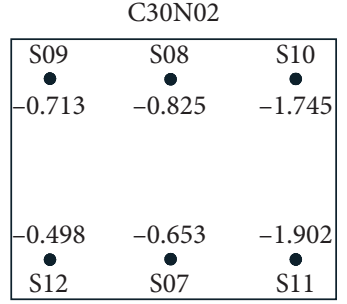

MRCR $=-1.056 \%$

SCR $=-2.905 \%$



MRCR $=-1.256 \%$

SCR $=-3.432 \%$

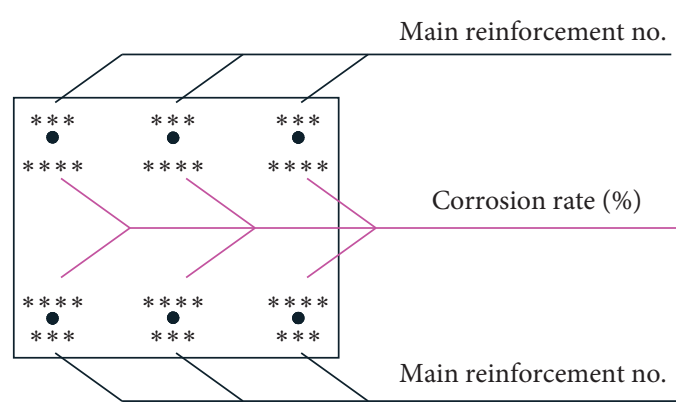

FIGURE 4: Corrosion rate results for each RC test beam.

TABLE 3: Optimizing curve fit for deflection $\left(d_{e f}\right)$ and corrosion time $(t)$.

\begin{tabular}{|c|c|c|c|}
\hline Type of fit & General expression & SSE $(\mathrm{mm})$ & R-square \\
\hline Exponential & $\begin{array}{c}d_{e f}=0.435 e^{2.087 \times 10^{-3} t} \\
d_{e f}=0.441 e^{1.783 \times 10^{-3} t}+3.955 \times 10^{-17} e^{0.242 t}\end{array}$ & $\begin{array}{l}0.00015 \\
0.00002\end{array}$ & $\begin{array}{l}0.9858 \\
0.9981\end{array}$ \\
\hline Polynomial & $\begin{array}{c}d_{e f}=1.066 \times 10^{-3} t+0.430 \\
d_{e f}=4.019 \times 10^{-6} t^{2}+4.24 \times 10^{-4} t+0.449 \\
d_{e f}=4.856 \times 10^{-8} t^{3}-7.679 \times 10^{-6} t^{2}+1.213 \times 10^{-3} t+0.435\end{array}$ & $\begin{array}{l}0.00024 \\
0.00006 \\
0.00003\end{array}$ & $\begin{array}{l}0.9775 \\
0.9948 \\
0.9968 \\
\end{array}$ \\
\hline Power & $\begin{array}{c}d_{e f}=0.302 t^{0.127} \\
d_{e f}=5.652 \times 10^{-5} t^{1.572}+0.453\end{array}$ & $\begin{array}{l}0.00137 \\
0.00006\end{array}$ & $\begin{array}{l}0.8709 \\
0.9941\end{array}$ \\
\hline
\end{tabular}

TABLE 4: Optimizing curve fit for frequency $(f)$ and corrosion time $(t)$.

\begin{tabular}{lccc}
\hline Type of fit & General expression & SSE (mm) & R-square \\
\hline \multirow{2}{*}{ Exponential } & $f=23.28 e^{-4.902 \times 10^{-4} t}$ & 0.00613 & 0.9944 \\
& $f=23.33 e^{-5.38 \times 10^{-4} t}+1.135 \times 10^{-5} e^{6.746 \times 10^{-2} t}$ & 0.00031 & 0.9997 \\
\hline \multirow{3}{*}{ Polynomial } & $f=-1.096 \times 10^{-2} t+23.27$ & 0.00753 & 0.9932 \\
& $f=2.435 \times 10^{-5} t^{2}-1.485 \times 10^{-2} t+23.38$ & 0.00080 & 0.9993 \\
\multirow{2}{*}{ Power } & $f=1.905 \times 10^{-7} t^{3}-2.155 \times 10^{-5} t^{2}-1.176 \times 10^{-2} t+23.33$ & 0.00048 & 0.9996 \\
\hline
\end{tabular}

Figure 5(a) demonstrates that tendency of deflection changes with time, and Figure 5(b) demonstrates that tendency of natural frequency changes with time. We can see that the deflection gradually increases with time which means the stiffness diminishes. And the natural frequency decreases with time which also means that the stiffness diminishes. The same changes in law of structural stiffness with time is concluded according to static and dynamic test results. The corresponding fitting curves and equations are obtained and shown in Figure 5.

As is well known, the midspan deflection of simply supported beam structures is inversely proportional to stiffness. In this experiment, the stiffness of the simply supported beam is reduced due to steel corrosion. This led to the slope of deflection increase with time as is shown in Figure 5(a). At the same time, the modal parameters especially natural frequencies were sensitive to the changes in stiffness. Razak and Choi [24] come to the conclusion that the stiffness reduction is square the natural frequency reduction. Thus, the gradient of natural frequency decreases with time as is shown in Figure 5(b).

It is worth noting that this experiment lasted for 140 days. The maximum mean value of main reinforcement corrosion rate (MRCR) is -1.492 percent, and the maximum mean value of stirrup corrosion rate (SCR) is -4.083 percent. 


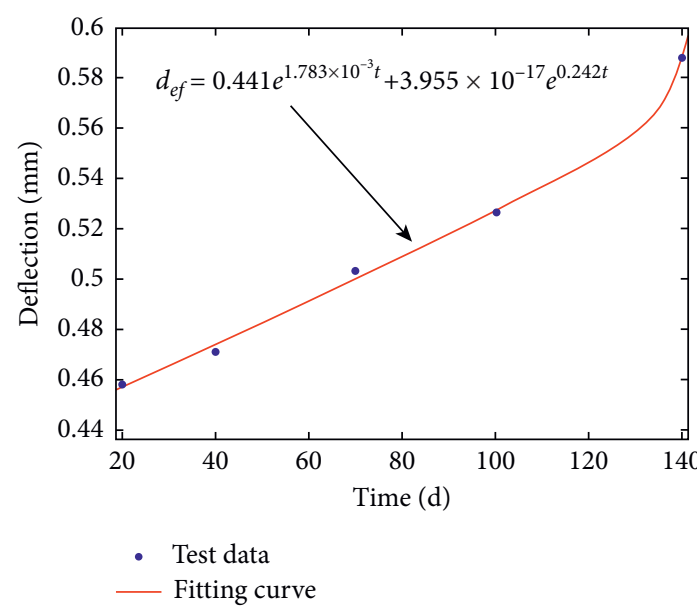

(a)

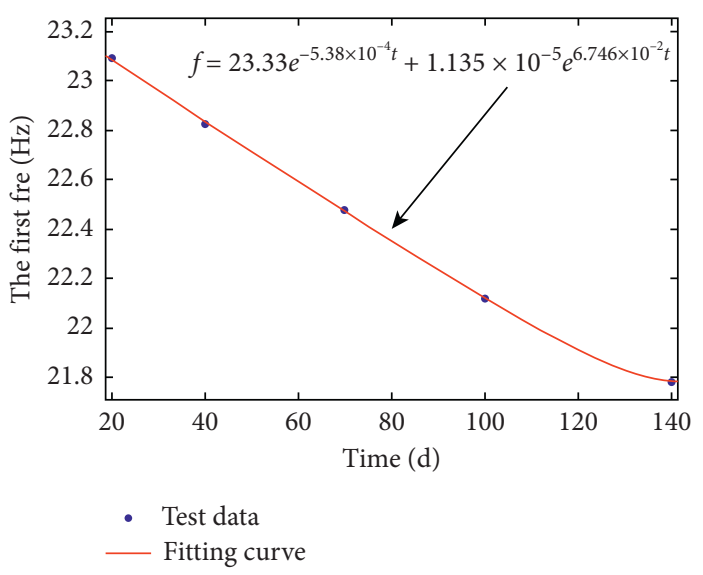

(b)

Figure 5: Static and dynamic test results (C30N04): (a) static test result and (b) dynamic test result.

Due to the lack of longer time and more severe corrosion degree data, predicting accuracy of the deflection and natural frequency over longer time and more severe corrosion is hard to guarantee at the moment.

\subsection{Analysis of the Relationship between the Natural Fre-} quency and Corrosion Depth. In actual structures, the corrosion depth is obtained from regular testing. Many methods of corrosion depth testing have been proposed and applied to actual structures $[30,31]$. Therefore, we need to find out the relationship between natural frequencies and corrosion depth.

It is assumed that the surface of the steel is uniformly corroded. Corrosion depth can be calculated from steel corrosion rate $R_{s}$. The expression of corrosion depth can be written as

$$
d=\frac{D}{2}\left(1-\sqrt{1-R_{s}}\right)
$$

where $d$ denotes corrosion depth and $D$ denotes the diameter of initial steel.

Table 5 shows the optimizing curve fit for natural frequency and the corrosion depth of the main reinforcement. Table 6 shows the optimizing curve fit for natural frequency and the corrosion depth of the stirrup. According to the calculation results of SSE and R-square, we selected equation (5) to establish the relationship between natural frequency $(f)$ and the corrosion depth of the main reinforcement $\left(d_{c m}\right)$, and equation (6) to express the relationship between natural frequency $(f)$ and the corrosion depth of the stirrup $\left(d_{\mathrm{cs}}\right)$ :

$$
f=-3.159 \times 10^{-4} d_{c m}^{3}+3.187 \times 10^{-2} d_{c m}^{2}-1.124 d_{c m}+35.77
$$

$f=-1.098 \times 10^{-4} d_{c s}^{3}+1.875 \times 10^{-2} d_{c s}^{2}-1.098 d_{c s}+43.91$.
Figure 6(a) shows the test data regarding natural frequency at each corrosion depth of the main reinforcement. The curve fitting between natural frequency $(f)$ and the corrosion depth of the main reinforcement $\left(d_{c m}\right)$ is obtained through the polynomial model. Figure 6(b) demonstrates the test data regarding natural frequency at each corrosion depth of the stirrup. The curve fitting between natural frequency $(f)$ and the corrosion depth of the stirrup $\left(d_{\mathrm{cs}}\right)$ is obtained through the polynomial model.

Steel corrosion is a complex process regards as chemical and electronic chemical. The concrete cracks caused by corrosion expansive are the main factor effect on changes in natural frequency. The distribution and severity of concrete cracks caused by corrosion expansive are random. The relationship between natural frequency and corrosion depth is hard to quantitative study by theory analysis or by the FE simulation method. Experimental study is a very effective supplement research method. On the basis of previous theoretical research and qualitative analysis, the quantitative relationship between steel corrosion and natural frequency is obtained by the experimental study method in this paper. It can be seen that the theoretical analysis, FE simulation, and experimental study complement and promote each other in scientific research work.

In real cases, the corrosive depth should be obtained from the regular test or monitored in real time. According to the relationships between natural frequency and corrosion depth, we can estimate natural frequency changes under the influence of corrosion depth. Furthermore, the effect of corrosion on natural frequency of reinforced concrete beams can be eliminate and accuracy natural frequency is identified. Through the results of this research, many structural damage identification methods can be applied in actual structures.

3.4. Discussion on the Effect of Composition of Concrete Mixes on Corrosion. Corrosion is affected by several factors such as temperature, humidity, and chloride concentration. In order 
TABle 5: Optimizing curve fit for natural frequency $(f)$ and the corrosion depth of the main reinforcement $\left(d_{c m}\right)$.

\begin{tabular}{lccc}
\hline Type of fit & General expression & SSE (mm) & R-square \\
\hline \multirow{2}{*}{ Exponential } & $f=24.93 e^{-3.705 \times 10^{-3} d_{c m}}$ & 0.03931 & 0.9644 \\
& $f=80.25 e^{-0.219 d_{c m}}+23.49 e^{2.035 \times 10^{-3} d_{c m}}$ & 0.00080 & 0.9993 \\
\hline \multirow{3}{*}{ Polynomial } & $f=-8.249 \times 10^{-2} d_{c m}+24.79$ & 0.04240 & 0.9616 \\
& $f=3.716 \times 10^{-3} d_{c m}^{2}-0.304 d_{c m}+27.96$ & 0.00419 & 0.9962 \\
\multirow{2}{*}{ Power } & $f=-3.159 \times 10^{-4} d_{c m}^{3}+3.187 \times 10^{-2} d_{c m}^{2}-1.124 d_{c m}+35.77$ & 0.00044 & 0.9996 \\
\hline
\end{tabular}

TABle 6: Optimizing curve fit for natural frequency $(f)$ and the corrosion depth of the stirrup $\left(d_{\mathrm{cs}}\right)$.

\begin{tabular}{lccc}
\hline Type of fit & General expression & SSE (mm) & R-square \\
\hline \multirow{2}{*}{ Exponential } & $f=25.27 e^{-2.475 \times 10^{-3} d_{c m}}$ & 0.08363 & 0.9242 \\
& $f=92.11 e^{-0.115 d_{c s}}+22.68 e^{-7.085 \times 10^{-4} d_{c s}}$ & 0.02325 & 0.9789 \\
\hline \multirow{3}{*}{ Polynomial } & $f=-5.498 \times 10^{-2} d_{c s}+25.09$ & 0.08732 & 0.9209 \\
& $f=2.194 \times 10^{-3} d_{c s}^{2}-0.278 d_{c s}+30.57$ & 0.02704 & 0.9755 \\
\multirow{2}{*}{ Power } & $f=-1.098 \times 10^{-4} d_{c s}^{3}+1.875 \times 10^{-2} d_{c s}^{2}-1.098 d_{c s}+43.91$ & 0.02254 & 0.9796 \\
\hline
\end{tabular}

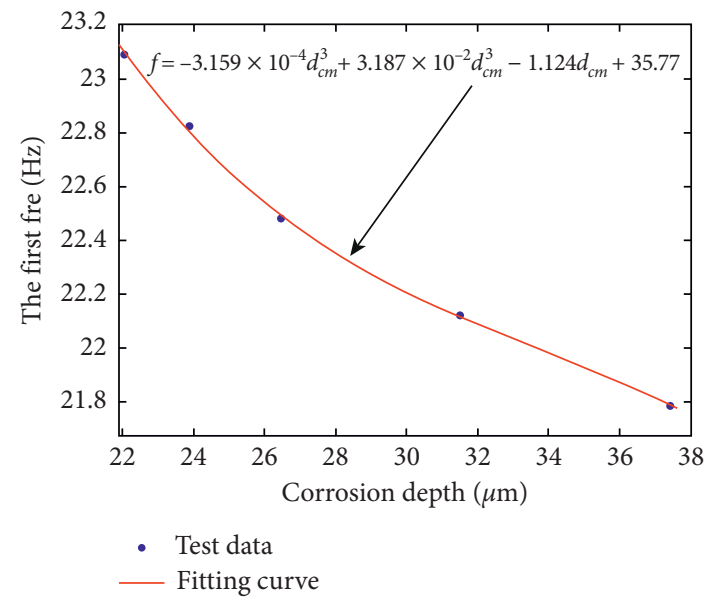

(a)

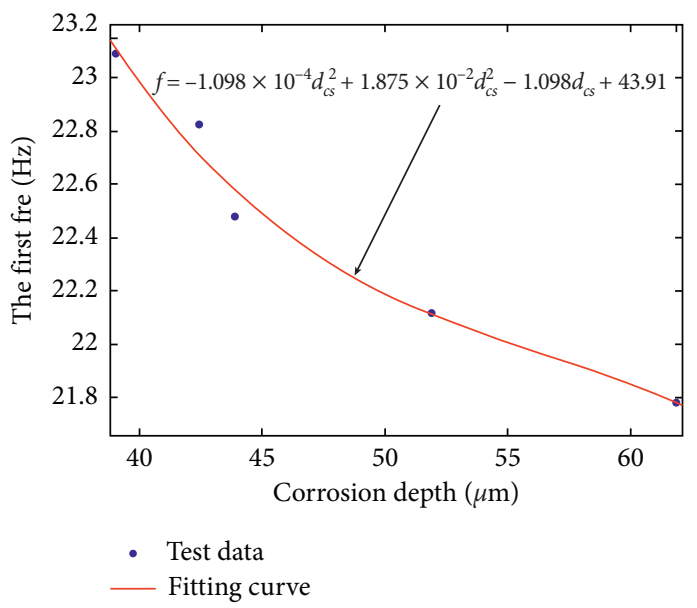

(b)

FIGURE 6: Relation between corrosion depth and modal frequency: (a) main reinforcement and (b) stirrup.

to decrease the corrosion rate, a great many measures and methods have been adopted to control temperature and reduce humidity and chloride concentration so as to provide idealized working conditions for concrete. Furthermore, the composition on concrete mixes is another important factor affecting the steel corrosion in concrete [32, 33]. Hussian and Al-Saadoun [34] concluded that alkali content of cement appears to have an inhibiting effect on its chloridebinding capacity. Hartt and Nam [35] studied the effect of cement alkalinity on time-to-corrosion of reinforcing steel in concrete. The results revealed greater time-to-corrosion for corrosion initiation for the higher cement of equivalent alkalinity. Tawfik et al. [36] studied the effect of nanomaterial on corrosion rate of steel reinforcement embedded in high-performance concrete. Stefanoni et al. [37] discovered that hydration activator and accelerator, usually contains $\mathrm{NaOH}$ and $\mathrm{Ca}\left(\mathrm{NO}_{3}\right)_{2}$, considerably increase the steel corrosion rate in carbonated concrete. Therefore, the effect of composition of concrete mixes on corrosion is an important research content. In fact, steel corrosion affects by not only alkali content of cement, but also the active properties of aggregates, aggregate gradation, and void fraction. In addition, microcracks in the working process of concrete components aggravate corrosion rate. Although this paper does not study these contents, it is a significant aspect of steel corrosion problem and also one of the import research directions of our research group.

\section{Conclusions}

The research has achieved its primary purpose of analyzing and testing the relationship between corrosion depth and 
natural frequency. A total of five RC test beams were subjected to static and dynamic testing in an accelerated corrosion environment. The main conclusions obtained from this study are as follows.

Steel corrosion rate test results demonstrate that the stirrup corrosion rate is much higher than the main reinforcement corrosion rate in the same environment. Because the thickness of cover of the stirrup is less than that of the main reinforcement, the stirrup begins to rust first.

Static and dynamic test results obtained for both deflection and natural frequency in an accelerated corrosion environment fit in well with our theoretical knowledge. That is, the deflection of RC test beams increases with corrosion rate of steel, and the natural frequency of RC test beam decreases with corrosion rate of steel.

General expression of the relationship between corrosion rate and natural frequency has been established through the fitting curve method. The polynomial model has been selected for establishing the relationship between steel (including the main reinforcement and stirrup) corrosion rate and natural frequency, since its SSE is closer to 0 and $\mathrm{R}$-square is closer to 1 .

For the need of field test, the optimizing curve fit and general expression for natural frequency and the corrosion depth are analyzed. The polynomial model has been determined for establishing the relationship between steel corrosion depth and natural frequency according the analysis of SSE and R-square.

Although corrosion is only one factor that affects the natural frequency change of the reinforced concrete beam. The findings of this study help to discriminate the cause of reinforced concrete natural frequency change, to identify the frequency changes caused by structural damage, and to apply many structural damage identification method. The results provide useful insight and an applicable model for the use of modal parameters to detect damage in a structural health monitoring (SHM) system of concrete structures.

\section{Data Availability}

The underlying data supporting the results of the study can be found in this paper.

\section{Conflicts of Interest}

The authors declare that they have no conflicts of interest.

\section{Acknowledgments}

This work was supported by Beijing Natural Science Foundation (8192046); Project of Basic Scientific Research Operating Expenses of Research Institute of Highway Ministry of Transport (2019-0102, 2018-9025, and 20189027); Subject of Project of National Key Fundamental Research Development Program (2013CB036305); and Ministry of Transport of the People's Republic of China (2015318J38230). These supports are gratefully acknowledged.

\section{References}

[1] V. Meruane and W. Heylen, "Structural damage assessment under varying temperature conditions," Structural Health Monitoring, vol. 11, no. 3, pp. 345-357, 2012.

[2] S. Qin and Z. Gao, "Developments and prospects of long-span high-speed railway bridge technologies in China," Engineering, vol. 3, no. 6, pp. 787-794, 2017.

[3] J. Rhee, H. Kim, C. Ock, and J. Choi, "An investigation of the deterioration characteristics of concrete bridge decks with asphalt concrete in Korea," KSCE Journal of Civil Engineering, vol. 22, no. 2, pp. 613-621, 2018.

[4] Y. Xia, H. Nassif, E. S. Hwang, and D. Linzell, "Optimization of design details in orthotropic steel decks subjected to static and fatigue loads," Transportation Research Record: Journal of the Transportation Research Board, vol. 2331, no. 1, pp. 14-23, 2013.

[5] M. B. Anoop and K. Balaji Rao, "Application of fuzzy sets for remaining life assessment of corrosion affected reinforced concrete bridge girders," Journal of Performance of Constructed Facilities, vol. 21, no. 2, pp. 166-171, 2007.

[6] M. Pour-Ghaz, O. B. Isgor, and P. Ghods, "The effect of temperature on the corrosion of steel in concrete. Part 1: simulated polarization resistance tests and model development," Corrosion Science, vol. 51, no. 2, pp. 415-425, 2009.

[7] S.-L. James Hu, S. Wang, and H. Li, "Cross-modal strain energy method for estimating damage severity," Journal of Engineering Mechanics, vol. 132, no. 4, pp. 429-437, 2006.

[8] O. Huth, G. Feltrin, J. Maeck, N. Kilic, and M. Motavalli, "Damage identification using modal data: experiences on a prestressed concrete bridge," Journal of Structural Engineering, vol. 131, no. 12, pp. 1898-1910, 2005.

[9] R. Bolton, C. Sikorsky, S. Park, S. Choi, and N. Stubbs, "Modal property changes of a seismically damaged concrete bridge," Journal of Bridge Engineering, vol. 10, no. 4, pp. 415-428, 2005.

[10] T. M. Ha, S. Fukada, and K. Torii, "Long-term vibration monitoring of the effects of temperature and humidity on PC girders with and without fly ash considering ASR deterioration," Shock and Vibration, vol. 2017, Article ID 5468950, 23 pages, 2017.

[11] L. Gelman, "The new frequency response functions for structural health monitoring," Engineering Structures, vol. 32, no. 12 , pp. 3994-3999, 2010.

[12] A. Iranmanesh and F. Ansari, "Energy-based damage assessment methodology for structural health monitoring of modern reinforced concrete bridge columns," Journal of Bridge Engineering, vol. 19, no. 8, Article ID A4014004, 2014.

[13] B. Wu, G. Wu, H. Lu, and D. C. Feng, "Stiffness monitoring and damage assessment of bridges under moving vehicular loads using spatially-distributed optical fiber sensors," Smart Materials and Structures, vol. 26, no. 3, Article ID 035058, 2017.

[14] I. Mekjavic and D. Damjanovic, "Damage assessment in bridges based on measured natural frequencies," International Journal of Structural Stability and Dynamics, vol. 17, no. 2, 2017.

[15] S. Sun, L. Liang, M. Li, and X. Li, "Vibration-based damage detection in bridges via machine learning," KSCE Journal of Civil Engineering, vol. 22, no. 12, pp. 5123-5132, 2018.

[16] Y. Oshima, K. Yamamoto, and K. Sugiura, "Damage assessment of a bridge based on mode shapes estimated by responses of passing vehicles," Smart Structures and Systems, vol. 13, no. 5, pp. 731-753, 2014. 
[17] P. Moser and B. Moaveni, "Environmental effects on the identified natural frequencies of the dowling hall footbridge," Mechanical Systems and Signal Processing, vol. 25, no. 7, pp. 2336-2357, 2011.

[18] H. Sohn, M. Dzwonczyk, E. G. Straser, A. S. Kiremidjian, K. H. Law, and T. Meng, "An experimental study of temperature effect on modal parameters of the Alamosa canyon bridge," Earthquake Engineering \& Structural Dynamics, vol. 28 , no. 8, pp. 879-897, 1999.

[19] S. Mohammadi Esfarjani, M. Salehi, and A. Ghassemi, "Effect of the multiple damages and temperature changes on the natural frequency," Journal of Theoretical and Applied Mechanics, vol. 55, no. 3, pp. 813-822, 2017.

[20] H. Nandan and M. P. Singh, "Effects of thermal environment on structural frequencies: part I-a simulation study," Engineering Structures, vol. 81, pp. 480-490, 2014.

[21] L. Zhang and L. Sun, "Effect of concrete carbonation on natural frequency of reinforced concrete beams," Advances in Structural Engineering, vol. 20, no. 3, pp. 316-330, 2017.

[22] W. T. Lin, Y. C. Wu, and A. Cheng, "Effect of corrosion on the natural frequency in a scaled-down reinforced concrete containment vessel specimen," Materials Research Innovations, vol. 18, p. 5, 2014.

[23] G.-R. Gillich, Z. I. Praisach, V. Iancu, H. Furdui, and I. Negru, "Natural frequency changes due to severe corrosion in metallic structures," Strojniški vestnik-Journal of Mechanical Engineering, vol. 61, no. 12, pp. 721-730, 2015.

[24] H. A. Razak and F. C. Choi, "The effect of corrosion on the natural frequency and modal damping of reinforced concrete beams," Engineering Structures, vol. 23, no. 9, pp. 1126-1133, 2001.

[25] R. Rahgozar and Y. Sharifi, "Remaining fatigue life of corroded steel structural members," Advances in Structural Engineering, vol. 14, no. 5, pp. 881-890, 2011.

[26] Y. Zhou, L. Sun, and Z. Peng, "Mechanisms of thermally induced deflection of a long-span cable-stayed bridge," Smart Structures and Systems, vol. 15, no. 3, pp. 505-522, 2015.

[27] M. Wasim and R. R. Hussain, "Passive film formation and corrosion initiation in lightweight concrete structures as compared to self compacting and ordinary concrete structures at elevated temperature in chloride rich marine environment," Construction and Building Materials, vol. 78, pp. 144-152, 2015.

[28] Y. A. Villagrán Zaccardi, A. Bértora, and A. A. Di Maio, "Temperature and humidity influences on the on-site active marine corrosion of reinforced concrete elements," Materials and Structures, vol. 46, no. 9, pp. 1527-1535, 2013.

[29] N. Otsuki, M. S. Madlangbayan, T. Nishida, T. Saito, and M. A. Baccay, "Temperature dependency of chloride induced corrosion in concrete," Journal of Advanced Concrete Technology, vol. 7, no. 1, pp. 41-50, 2009.

[30] D. A. N. Jr, S. F. Da, M. T. Guimarã£Es, and M. D. Pereira, "Corrosion assessment of steel bars used in reinforced concrete structures by means of eddy current testing," Sensors, vol. 16, no. 1, p. 15, 2015.

[31] H. Zhang, L. Liao, R. Zhao, J. Zhou, M. Yang, and Y. Zhao, “A new judging criterion for corrosion testing of reinforced concrete based on self-magnetic flux leakage," International Journal of Applied Electromagnetics and Mechanics, vol. 54, no. 1, pp. 123-130, 2017.

[32] T. Lorentz and C. French, "Corrosion of reinforcing steel in concrete: effects of materials, mix composition, and cracking," Materials Journal, vol. 92, no. 2, pp. 181-190, 1995.
[33] P. F. Marques and A. Costa, "Service life of RC structures: carbonation induced corrosion. Prescriptive vs. performancebased methodologies," Construction and Building Materials, vol. 24, no. 3, pp. 258-265, 2010.

[34] S. E. Hussain and S. Al-Saadoun, "Effect of cement composition on chloride binding and corrosion of reinforcing steel in concrete," Cement and Concrete Research, vol. 21, no. 5, pp. 777-794, 1991.

[35] W. H. Hartt and J. Nam, "Effect of cement alkalinity on chloride threshold and time-to-corrosion of reinforcing steel in concrete," Corrosion, vol. 64, no. 8, pp. 671-680, 2008.

[36] T. A. Tawfik, M. A. El-Yamani, S. Abd El-Aleem, A. Serag Gabr, and G. M. Abd El-Hafez, "Effect of nano-silica and nano-waste material on durability and corrosion rate of steel reinforcement embedded in high-performance concrete," Asian Journal of Civil Engineering, vol. 20, no. 1, pp. 135-147, 2019.

[37] M. Stefanoni, U. Angst, and B. Elsener, "Influence of calcium nitrate and sodium hydroxide on carbonation-induced steel corrosion in concrete," Corrosion, vol. 75, no. 7, 2019. 